\title{
Nitrous Oxide Occupational Exposure in Conscious Sedation Procedures in Endoscopic Ambulatories: A Pilot Retrospective Observational Study in an Italian Hospital
}

Ivan Borrelli ( $\boldsymbol{\nabla}$ ivan.borrelli@unicatt.it )

Catholic University of the Sacred Heart https://orcid.org/0000-0002-6361-8823

Roberta Pastorino

Fondazione Policlinico Universitario A. Gemelli IRCCS

Rodolfo Buccico

AO dei Colli

Paolo Emilio Santoro

Fondazione Policlinico Universitario A. Gemelli IRCCS

Umberto Moscato

Catholic University of the Sacred Heart

\section{Research}

Keywords: occupational medicine, nitrous oxide, toxicology, operators exposure, anesthetic gas

Posted Date: May 18th, 2021

DOI: https://doi.org/10.21203/rs.3.rs-514255/v1

License: (c) (1) This work is licensed under a Creative Commons Attribution 4.0 International License.

Read Full License 
Title

\section{Nitrous oxide occupational exposure in conscious sedation procedures in endoscopic ambulatories: a pilot retrospective observational study in an Italian hospital}

Ivan Borrelli', Roberta Pastorino², Rodolfo Buccicos ${ }^{3}$, Paolo Emilio Santoro ${ }^{2}$ and Umberto Moscato $^{1-2}$

\section{Background:}

Nitrous oxide is widely used to induce sedation; however, its use outside of operating rooms - such as in ambulatory rooms - is not properly controlled by norms. In the lack of supervision, there is a chance of workplace exposures for the operators engaged in the outpatient use of nitrous oxide. The aim of this research is to assess nitrous oxide exposure in gastroenterology outpatient settings.

\section{Methods:}

We performed an observational study with a first step marked by nitrous oxide environmental testing in a gastroenterology outpatient care where colonoscopies were practiced; environmental research was supported by biological monitoring with urinary $\mathrm{N} 2 \mathrm{O}$ analysis in exposed operators. The research was conducted in the absence and then in the presence of a collective security device (Niki mask).

\section{Results:}

The study was rolled out in 10 sessions of day shift procedures, totaling 4105 samples. The average nitrous oxide concentration in the environment was 27.58 (SD 1.76) and 449.59 (SD 35.29), respectively with and without Niki Mask; the distribution of gases in the environment under investigation was not homogeneous (Anova test p.001). Biological testing revealed a substantial rise 
in urinary concentration of 8.97 (p.001) between the start and the end of the shift, and the use of the Niki mask was effective $(\mathrm{p}=.003)$.

\section{Conclusions:}

The exposure levels reported in environmental sampling exceed the limits of $50 \mathrm{ppm}$ (the value set for operating rooms in Italy) as well as the value of $25 \mathrm{ppm}$ (NIOSH threshold value), indicating a significant issue in the outpatient use of nitrous oxide. It is evident that technical measures are needed to contain the occupational risk from Nitrous oxide exposure outside of operating rooms, and that even the basic use of Niki masks would not be sufficient to minimize professional exposure and protect workers; for the exposure results detected in this research, it is also plain that exposures must be subject to health surveillance.

Keywords: occupational medicine, nitrous oxide, toxicology, operators exposure, anesthetic gas

\section{Background}

Sedation is an integral feature of any gastrointestinal endoscopic treatment since it helps gastroenterologists to relieve patient anxiety and distress while optimizing the endoscopic exam's result [1]. Nitrous oxide gas, as well as benzodiazepines and opioids, can be used to induce conscious sedation [2].

Multiple research and reviews have thoroughly defined esophagogastroduodenoscopy (EGD) or upper endoscopy sedation monitoring. A basic diagnostic EGD is a reasonably fast treatment that only involves 30 minutes of sedation. Sedation may be given for diagnostic upper EGD with either mild sedation or controlled anesthesia treatment (MAC) with $[3,4]$. Nitrous oxide-sedation is also a safe and reliable alternative for patients undergoing digestive endoscopy [5,6,7].

The use of moderate to deep sedation is becoming more common, which can be difficult for both anesthesiologists and gastroenterologists [8]. While deeper sedation helps gastroenterologists to 
conduct more complex procedures, there is a risk of multiple cardiopulmonary complications, particularly in high-risk patients $[8,9,10]$.

Nitrous oxide has proved clinical efficacy, but at such ambient levels, it may pose a health threat to medical professionals who are chronically exposed.

The study seeks to detect the critical issues with the use of this anesthetic gas in ambulatory settings (outside of surgical rooms); the study aims to analyze the exposure conditions of health professionals engaged in these diagnostic procedures; one of the major issues in nitrous oxide conscious sedation is the definition of reference values in ambulatory rooms that are not comparable to those established in operating rooms; to this end, it should be noted that current legislation in Italy establishes environmental criteria for the use of $\mathrm{N} 2 \mathrm{O}$ in operating rooms but no specific references for outpatient settings .

In terms of occupational toxicology, the most important factor is obviously persistent exposure to $\mathrm{N} 2 \mathrm{O}$; literature cites numerous findings that correlate chronic exposure to nitrous oxide with the onset of adverse effects on workers exposed to dental procedures. The most often reported side effects are: an increase in the rate of spontaneous abortion, infertility and reproductive difficulties, congenital anomalies and fetal growth delay; an increase in the incidence of cancer in the uterine cervix and kidney, liver diseases; adverse effects on bone marrow function and immune system, generalized neurological disorders and psychomotor dysfunction $[11,12,13,14,15,16]$.

Occupational exposure may trigger nausea, irritability, and headache [17,18], as well as liver, renal, and hematopoietic system defects [19,20], and neurobehavioral shifts [21]. Furthermore, exposure to waste anesthetic gases is linked to an increased occurrence of abortion/miscarriage [22,23], decreased fertility [24], and birth defects, which are particularly linked to N2O [25]. Chronic exposure can also affect DNA [26].

The study's goal, in addition to evaluating staff occupational exposure, is to assist the scientific community in determining the reference environmental values specific for endocrinology ambulatories that use nitrous oxide, with a focus on the pediatric background. 
The study's key endpoint measures was associated with the determination of nitrous oxide environmental and biological concentrations during gastrointestinal endoscopic sessions. These tests are taken to monitor the degree of anesthetic gas exposure among operators and to investigate the effectiveness of the preventive system (structure/implant features, anesthesia devices, work procedures, and human factors).

\section{Methods}

The study is made up of two parts: the first focuses on the interpretation of data obtained from N2O environmental monitoring, while the second is centered on biological monitoring data from exposed operators.

The environmental concentrations of nitrous oxide were detected using an instrument during four months for a total of 10 surveys. The instrument used for gas analysis is the photoacoustic spectrometer Innova-B\&K (Brüel \& Kjær, Denmark) "Multi-gas monitor model 1312” and InnovaB\&K (Brüel \& Kjær, Denmark) “Multi-sampler model 1309”. Measurements were performed using the instrument for the whole outpatient session. The measuring probes were placed in five different point in the ambulatory (Figure 1).

The environmental monitoring surveys were divided into two sessions: the first, in which patients were sedated with an $\mathrm{O} 2 / \mathrm{N} 2 \mathrm{O}$ mixture delivered without the use of an evacuation system, and the second, in which patients were sedated with the same $\mathrm{O} 2 / \mathrm{N} 2 \mathrm{O}$ mixture, but with the assistance of a mobile double mask evacuation system of type "NIKI 2002 Airnova" capable of intercepting the anesthetic gases that come out.

A descriptive study design was used to assess gas concentrations in a hospital's gastroenterology ambulatories. For environmental sampling results, the Shapiro-France analysis was used to measure data dissemination. The data was then stratified using the categorical variable relating to the use of the Niki mask. The t-Student parametric test was then used to analyze the averages in relation to the variable of Niki mask use; The ANOVA variance test was used instead for the study of the averages 
of the environmental levels of $\mathrm{N} 2 \mathrm{O}$ at the respective sample points, with the averages above two being corrected with the Bonferroni's test.

The study's participants were a team of health professionals who serve in the gastroenterology ambulatory for each colonoscopy session; the team included one gastroenterologist and one nurse. An operator with the qualification of prevention technician was interested in the environmental analysis and the preparation of urinary samples; biological sampling was performed on their urine for the biological analysis. The environmental data and urinary samples were analyzed in validated laboratories.

The samples were then analyzed in laboratory, by means of a Thermo Trace GC Ultra with Polaris Q Mass Spectrometer GC/MS System (IET-International Equipment Trading Ltd., Mundelein, Illinois, USA), and Thermo Direct Probe Controller (IET-International Equipment Trading Ltd., Mundelein, Illinois, USA). After urine sampling an immediate transfer of a urine aliquot to a hermetically sealed tube was therefore performed very quickly $(\mathrm{t}<1$ minute) so that the vapors loss was negligible $(<$ $5 \%$. The urines were then acidified with sulfuric acid (200 $\mu \mathrm{l}$ of $\mathrm{H} 2 \mathrm{~S} 049 \mathrm{~N}$ as antimicrobial agent) and stored for more than $24 \mathrm{~h}$. Collection was performed in environments free of pollution due to anesthetic gases. The vials, appropriately labeled, were transported to the laboratories, through a thermostatic thermal bag and stored at $4{ }^{\circ} \mathrm{C}$ up to the analysis.

A descriptive analysis of the $\mathrm{N} 2 \mathrm{O}$ concentrations of urine was performed. Due to the limited sample size, data distribution analysis was performed using the Shapiro-Wilk test. The t-test was thus used to compare the urinary concentration averages of $\mathrm{N} 2 \mathrm{O}$ for doctors and nurses at time 0 (start of shift), and the same was repeated at time 1. (end of shift). The t-test was also used to analyze $\mathrm{N} 2 \mathrm{O}$ averages between time $\mathrm{T} 0$ and $\mathrm{T} 1$ in participants who wore Niki masks and those who did not. Statistical significance was determined by $\mathrm{p}<.05$ values.

\section{Results}


The endoscopists and nurses engaged in the outpatient diagnostic procedure were hired for the study; the observation period lasted 10 days, and 48 patients were treated; diagnostic services were conducted during day shifts between 06:57 and 18:23.

\section{1 environmental analysis (Study 1)}

The $\mathrm{N} 2 \mathrm{O}$ levels in the environment were first stratified in order to compare the conditions under which $\mathrm{N} 2 \mathrm{O}$ is used without any emission control mechanism and then with the use of the control mechanism (Niki mask).

For a total of 10 days of observation, 4105 sequential samples were collected for each of the five detection stations; having discovered values well above the exposure limits (50ppm) in the absence of the use of containment mechanisms (Niki mask), it was decided to discontinue the experimentation in this way and continue only for samples with the use of Niki mask as a principle of safeguarding. We obtained 374 environmental determinations without using the Niki mask and 3731 with using this mask.

The average environmental concentration of $\mathrm{N} 2 \mathrm{O}$ in the air was 27.58 (SD 1.76) in the presence of Niki mask and 449.59 (DS 35.29) without the use of Niki. The difference in averages (with and without Niki) detected was largely significant $(\mathrm{p}<.001)$.

As mentioned - the environmental samplers - in the room were placed in five different places; the average concentrations at the individual points were determined (Table 1) noting a significant difference $(\mathrm{p}<.001)$ between the points even if with a low strength $(\mathrm{F} 16.42)$ and an $\mathrm{R} 2$ supporting the model only of .017.

Table 1- Average concentrations at different points

\begin{tabular}{|l|l|l|l|}
\hline Sampling point & number & Average & S.D. \\
\hline \multirow{3}{*}{ 1-Niki } & 749 & 40.00 & 85.47 \\
\cline { 2 - 4 } & 75 & 436.52 & 329.59 \\
\hline \multirow{2}{*}{ 2- head-window } & 748 & 23.59 & 43.23 \\
\cline { 2 - 4 } & 75 & 518.77 & 416.95 \\
\hline 3- head door & 747 & 26.57 & 46.19 \\
\hline
\end{tabular}




\begin{tabular}{|l|l|l|l|}
\hline & 75 & 424.73 & 308.18 \\
\hline \multirow{3}{*}{ 4- stabilized door } & 746 & 18.33 & 32.06 \\
\cline { 2 - 4 } & 75 & 446.06 & 319.51 \\
\hline \multirow{3}{*}{ 5- access } & 741 & 29.40 & 49.59 \\
\cline { 2 - 4 } & 73 & 421.11 & 348.20 \\
\hline \multirow{2}{*}{ Totale } & 3731 & 27.58 & 54.87 \\
\cline { 2 - 4 } & 373 & 449.59 & 346.62 \\
\hline
\end{tabular}

According to the Threshold Limit Value in the measurements in which the Niki mask was used, the levels set by NIOSH (25ppm) were exceeded 982 times, the levels set by Italian law for 'new' operating rooms (50ppm) 645 times and those for 'old' operating rooms (100ppm) 288 times.

There was a huge variation in environmental concentrations of $\mathrm{N} 2 \mathrm{O}$ at the different sample points (Table 2), implying that the lack of specific mechanisms for handling air flows and modifications causes areas of greater concentration and, as a result, greater professional exposures to anesthetic gases.

Table 2- Test Comparison of $\mathrm{N} 2 \mathrm{O}$ concentration (in $\mathrm{ppm}$ ) and sampling points (with * significant values, $\mathrm{p}<.05)$

\begin{tabular}{|l|l|l|l|l|}
\hline & 1-Niki & 2-head-window & 3-head door & 4- stabilized door \\
\hline 2- head-window & $-16.41^{*}$ & & & \\
& $\mathrm{p}<.001$ & & & \\
\hline 3- head door & $-13.43^{*}$ & 2.98 & & \\
& $\mathrm{p}<.001$ & $\mathrm{p}=1.00$ & & \\
\hline 4- stabilized door & $-21.67^{*}$ & -5.26 & -8.24 & \\
& $\mathrm{p}<.001$ & $\mathrm{p}=.62$ & $\mathrm{p}=.03^{*}$ & \\
\hline 5-access & $-10.60^{*}$ & 5.82 & $2.84^{*}$ & $11.08^{*}$ \\
& $\mathrm{p}<.001$ & $\mathrm{p}=.39^{*}$ & $\mathrm{p}<.001$ & $\mathrm{p}<.001$ \\
\hline
\end{tabular}

\subsection{Biological monitoring (Study 2)}

There was no discrepancy in urinary concentrations between doctors and nurses when the two classes of operators were examined. The exposure group (nurses and doctors) was then viewed as a single sample with a total of 16 determinations at $\mathrm{T} 0$ and 16 determinations at $\mathrm{T} 1$ 
The urine concentration averages of $\mathrm{NO} 2$ were analyzed, and the substantial reduction of urinary concentrations in those exposed to $\mathrm{NO} 2$ in the two groups compared: with Niki we obtained at T0 time and with the use of the mask a value of 1.17 (SD 2.32) and at T1 time a value of 10.14 (SD 3.78); without the mask the average at T0 time was of 1.01 (SD .39) and at T1 time was of 77.49 (SD 66.17); the protective effect of the Niki mask was then detected $(\mathrm{p}=.003)$.

The concentration variation at the start and end of the shift was relevant (p.001), with an average at T0 of 1.17 (SD 2.32) and at T1 of 10.14 (SD 3.77). (tab3).

\section{Discussion}

The first interesting finding from this research is that using anesthetic gases in conditions other than operating rooms exposes operators to a risk that exceeds the maximum values set by international agencies such as NIOSH (25 ppm, which is equal to $30 \mathrm{mg} / \mathrm{m} 3[27,28])$.

However, in an Italian context, there are limits on the environmental concentration of nitrous oxide that are controlled by specific provisions; Memorandum No 5 of 14 March 1989 of the Ministry of Health sets as the reference limit value for operating rooms the threshold of $50 \mathrm{ppm}(91 \mathrm{mg} / \mathrm{m} 3)-$ which rises to $100 \mathrm{ppm}$ for operating rooms that were already in existence at the time of Memorandum.

This research, in addition to discussing a topic not addressed by Italian regulations or national standards on $\mathrm{N} 2 \mathrm{O}$, highlights a professional field - ambulatory where medical gases are used - where operators are exposed to workplace hazards, revealing a deficiency in the health professionals' prevention and safety framework. Despite the limited sample size, the end-of-shift urinary concentration was observed to be 77.49 and $10.14 \mathrm{mg} / \mathrm{l}$ without and with a Niki mask, respectively, against an exposure limit of $27 \mathrm{mg} / \mathrm{l}$.

To be able to use a facility as a safe room for the use of anesthetic gases, mechanisms for reducing emissions and/or air exchange systems that can guarantee compliance with anesthetic gas exposure values must be provided. The use of the Niki Mask tested in this study seems to be a useful 
intervention to satisfy the reduction of environmental concentrations of $\mathrm{N} 2 \mathrm{O}$ below the expected values in the operating rooms; however, it should be noted that the average concentration is still higher than the values set for occupational exposures (NIOSH) of $25 \mathrm{ppm}$, and hence additional containment systems should be studied.

There was no noticeable variation in $\mathrm{N} 2 \mathrm{O}$ exposure between doctors and nurses, which was most likely due to their location in the room being near the same area examined by the sampler. In this regard, it is also worth noting that in the absence of complex air collection and control systems, there are areas of higher $\mathrm{N} 2 \mathrm{O}$ aggregation and areas with lower concentrations.

A final comment should be taken on the health surveillance of the operators involved, including the fact that it is noted that these operators, as well as counterparts working in the operating rooms, would join the health surveillance program for exposure to anesthetic gases.

The samplers were put in five different points as stated in the room; the average concentrations at the individual points were calculated (Table 3) and then a comparison between the averages and the Variance test (ANOVA) was performed, revealing a substantial difference (p.001) between the points despite a low intensity (F16.42) and an R2 supporting the model of just .017.

Table 3- Comparison of $\mathrm{N}_{2} \mathrm{O}$ urine concentration averages

\begin{tabular}{|l|l|l|l|l|l|l|}
\hline & Observations & Mean & S.E. & S.D. & $95 \%$ C.I. & p-value \\
\hline Operators T1 & 16 & 10.14 & .94 & 3.78 & $8.13 / 12.15$ & \\
\hline Operator T0 & 16 & 1.17 & .58 & 2.32 & $-.06 / 2.41$ & \\
\hline Difference & 16 & 8.97 & .88 & 3.53 & $7.09 / 10.85$ & $\mathrm{p}<.001$ \\
\hline \multicolumn{7}{|l|}{} \\
\hline Comparison of $\mathrm{N}_{2} \mathrm{O}$ urine concentration averages without the use of Niki mask \\
\hline Operators T1 & 4 & 77.49 & 33.09 & 66.17 & -27.80 a 182.79 & \\
\hline Operator T0 & 4 & .62 & .26 & .52 & -.21 a 1.45 & \\
\hline Difference & 4 & 76.87 & 33.00 & 66.00 & -28.13 a 181.88 & $\mathrm{p}=.10$ \\
\hline
\end{tabular}

The study appears to be rigorous in terms of what has been discovered in the context of environmental monitoring, with the number of measurements and sample size appearing large enough to show that outpatient environments need structural actions to minimize the workplace exposures of the operators 
involved; The section on biological monitoring seems to be interesting in terms of providing scientifically valid support for the assumption that outpatient exposures of healthcare professionals are at risk of $\mathrm{N} 2 \mathrm{O}$ exposure, but the small size of the observed sample should be noted, as should the need to expand the study to larger populations in order to provide greater consistency to the data collected in relation to the environmental monitoring.

\section{Conclusion}

The current study's findings lead to the need to deepen and enforce technical guidelines, requirements, and systems for the use of $\mathrm{N} 2 \mathrm{O}$ in ambulatory settings; in the Italian setting, it is apparent that law enforcement needs to properly identify the technical standards and exposure limit of $\mathrm{N} 2 \mathrm{O}$ outside the operating room.

This study emphasizes the importance of implementing additional precautions for operators who are exposed to endoscopic procedures in ambulatory facilities.

Finally, the authors would consider using nitrous oxide in conjunction with a gas scavenging device to reduce the operators' exposure.

This study also reveals that measuring the gas scavenging system is insufficient to secure operators, who would need to undergo health surveillance measures to track the medium to long-term effects. The authors intended to add to the debate over the concept of reference standards for nitrous oxide environmental concentrations by highlighting the lack of specific regulatory limits for medical procedures involving nitrous oxide in facilities other than operating rooms.

\section{Abbreviations}

Esophagogastroduodenoscopy (EGD); monitored anesthesia care (MAC); National Institute for Occupational Safety and Health (NIOSH); biological exposure index (BEI)

\section{Acknowledgements}


A special thanks goes to the personnel of the gastroenterology ambulatories of Fondazione Policlinico Universitario A. Gemelli IRCCS, Rome, Italy

\section{Funding}

No financial support was received for this study.

\section{Availability of data and materials}

The datasets used and/or analysed during the current study are available from the corresponding author on reasonable request.

\section{Ethics approval and consent to participate:}

Not applicable. All methods were carried out in accordance with the relevant guidelines and regulations and approved by the institution where they were applied. The data is completely anonymous with no personal information being collected and the data are limited to topics that are strictly within the professional competence of the participants. The collection of data was carried out in accordance with national legislation on safety and health at work. According to the legislation the Employer must investigate the issues of research (ethical issues and implications for occupational well-being) in order to meet all legal obligations. Among the obligations of the employer there is also that of having to communicate and transmit to the company representations the data of the investigations carried out after having made them anonymous. Workers, within their employment relationship, contractually authorize the processing of privacy and consent to all procedures useful for the fulfilment of legal obligations in the field of health and safety at work. For what said there is no need for further approval by an Ethics Board; the absence of any further evaluation by the Ethics Committee is also due to the fact that research topics do not require either diagnostic or therapeutic intervention by any subject. 


\section{Consent for publication}

Not applicable.

\section{Competing interests}

There are no financial conflicts of interest related to the material presented.

\section{Authors' contributions}

UM was responsible for the urine analyses and their interpretation and was involved in the conception and design of the study, data analysis and interpretation, manuscript writing and final approval of the manuscript;

IB was involved in the conception and design of the study, data analysis and interpretation, manuscript writing and literature review

$\mathrm{RP}$ was involved in the design of study and data analysis

$\mathrm{RB}$ was involved in data analysis, manuscript writing and literature review

PES was involved in the design of study and data analysis

\section{Author details}

${ }^{1}$ Life Sciences and Public Health Department, Catholic University of the Sacred Heart, Rome, Italy;

2 Department of Woman and Child Health and Public Health-Public Health Area, Fondazione Policlinico Universitario A. Gemelli IRCCS, 00168 Rome, Italy

${ }^{3}$ Health Department, AO dei Colli, Naples, Italy;

\section{Bibliografia}


1. Wadhwa V, Vargo JJ. Sedation and monitoring in endoscopy. In: Chandrasekhara V, Elmunzer BJ, Khashab MA, Muthusamy VR. Clinical gastrointestinal endoscopy, 3rd ed. Philadelphia: Elsevier; 2018. pp. 81-90. eBook ISBN:9780323448642

2. Robertson AR, Kennedy NA, Robertson JA, Church NI, Noble CL. Colonoscopy quality with Entonox $\left({ }^{\circledR}\right) \mathrm{vs} \quad$ intravenous conscious sedation: 18608 colonoscopy retrospective study. World J Gastrointest Endosc. 2017; 9(9): 471-479. https://doi.org/10.4253/wjge.v9.i9.471.

3. Sharp CD, Tayler E, Ginsberg GG. Anesthesia for routine and advance dupper gastrointestinal endoscopic procedures. Anesthesiol Clin 2017;35(4):669-677. https://doi.org/10.1016/j.anclin.2017.08.006.

4. Wadhwa V, Gupta K, Vargo JJ. Monitoring standards in sedation and analgesia: the odyssey of capnography in sedation for gastroenterology procedures. Curr Opin Anaesthesiol. 2019;32(4):453-456. https://doi.org/10.1097/aco.0000000000000756.

5. Moscato U, Pattavina F, Zaffina S, et al. Protossido d'azoto a basso tenore. Risk assessment e risk management. G Ital Med Lav Erg. 2016;38(3):232-4.

6. Wang CX, Wang J, Chen YY, Wang JN, Yu X, Yang F, Sun SY. Randomized controlled study of the safety and efficacy of nitrous oxide-sedated endoscopic ultrasound-guided fine needle aspiration for digestive tract diseases. World J Gastroenterol. 2016;22(46):1024210248. doi: 10.3748/wjg.v22.i46.10242.

7. Ball AJ, Campbell JA, Riley SA. Nitrous oxide use during colonoscopy: a national survey of English screening colonoscopists. Frontline Gastroenterol. 2014;5(4):254-259. doi: 10.1136/flgastro-2014-100446.

8. Goudra B, Singh PM. Airway management during upper GI endoscopic procedures: state of the art review. Dig Dis Sci 2017;62:45-53. https://doi.org/10.1007/s10620-016-4375-z

9. Notini-Gudmarsson AK, Dolk A, Jakobsson J, Johansson C. Nitrous oxide: a valuable alternative for pain relief and sedation during routine colonoscopy. Endoscopy. 1996;28(3):283-7. https://doi.org/10.1055/s-2007-1005454. 
10. Fich A, Efrat R, Sperber AD, Wengrower D, Goldin E. Nitrous oxide inhalation as sedation for flexible sigmoidoscopy. Gastrointest Endosc. 1997;45(1):10-2. https://doi.org/10.1016/s0016-5107(97)70296-7.

11. Cohen E, Brown B, Wu J, et al. Occupational disease in dentistry and chronic exposure to trace anesthetic gases. J Am Dent Assoc. 1980;101(1):21-31. https://doi.org/10.14219/jada.archive.1980.0345.

12. Gutmann L, Johnsen D. Nitrous oxide-induced myeloneuropathy: report of cases. J Am Dent Assoc. 1981;103(2):239-41. https://doi.org/10.14219/jada.archive.1981.0271.

13. Vieira E, Cleaton-Jones PE, Mayes D. Effects of intermittent $0.5 \%$ nitrous oxide/air on the fertility of male rats and the post-natal growth of their offspring. Anaesthesia. 1983;38:31923. https://doi.org/10.1111/j.1365-2044.1983.tb10452.x

14. Eger EI. Nitrous Oxide/N2O. 2nd ed. New York: Elsevier; 1984. ISBN-13 : 978-0444008602

15. Rowland A, Baird D, Weinberg C, et al. Reduced fertility among women employed as dental assistants exposed to high levels of nitrous oxide. New Engl J Med. 1992;327(14):993-7. https://doi.org/10.1056/nejm199210013271405.

16. Zaffina S, Lembo M, Gilardi F, Bussu A, Pattavina F, Tucci MG, Moscato U, Raponi M, Derrico P, Galeotti A, Camisa V. Nitrous oxide occupational exposure in conscious sedation procedures in dental ambulatories: a pilot retrospective observational study in an Italian pediatric hospital. BMC Anesthesiol. 2019;19(1):42. https://dx.doi.org/10.1186\%2Fs12871019-0714-x.

17. Plummer JL, Sandison CH, Ilsley AH, Cousins MJ. Attitudes of anaesthetists and nurses to anaesthetic pollution. Anaesth Intensive Care. 1987;15:411-20. https://doi.org/10.1177/0310057x8701500410.

18. Saurel-Cubizolles MJ, Estryn-Behar M, Maillard MF, Mugnier N, Masson A, Monod G. Neuropsychological symptoms and occupational exposure to anaesthetics. $\mathrm{Br} \quad \mathrm{J}$ Ind Med. 1992;49:276-81. https://dx.doi.org/10.1136\%2Foem.49.4.276.

19. Green CJ. Anaesthetic gases and health risks to laboratory personnel: a review. Lab Anim. 1981;15:397-403. https://doi.org/10.1258/002367781780952843. 
20. Franco G, Marraccini P, Santagostino G, Filisetti P, Preseglio I. Behaviour of urinary D-glucaric acid excretion in surgical patients and anaesthesiology staff acutely exposed to isoflurane and nitrous oxide. Med Lav. 1991 Nov-Dec;82(6):527-32. PMID: 1803214.

21. Lucchini R, Placidi D, Toffoletto F, Alessio L. Neurotoxicity in operating room personnel working with gaseous and nongaseous anesthesia. Int Arch Occup Environ Health. 1996;68(3):188-92. doi: 10.1007/BF00381630.

22. Rowland AS, Baird DD, Shore DL, Weinberg CR, Savitz DA, Wilcox AJ. Nitrous oxide and spontaneous abortion in female dental assistants. Am J Epidemiol. 1995;141(6):531-8. doi: 10.1093/oxfordjournals.aje.a117468.

23. Boivin JF. Risk of spontaneous abortion in women occupationally exposed to anaesthetic gases: a meta-analysis. Occup Environ Med. 1997;54:541-8. https://dx.doi.org/10.1136\%2Foem.54.8.541.

24. Ahlborg G Jr, Axelsson G, Bodin L. Shift work, nitrous oxide exposure and subfertility among Swedish midwives. Int J Epidemiol. 1996;25(4):783-90. doi: 10.1093/ije/25.4.783.

25. Bodin L, Axelsson G, Ahlborg G Jr. The association of shift work and nitrous oxide exposure in pregnancy with birth weight and gestational age. Epidemiology. 1999 Jul;10(4):429-36. doi: 10.1097/00001648-19990700000012

26. Costa Paes ER, Braz MG, Lima JT, Gomes da Silva MR, Bentes de Sousa L, Lima ES, Carvalho de Vasconcellos M, Cerqueira Braz JR. DNA damage and antioxidant status in medical residents occupationally exposed to waste anesthetic gases. Acta Cir Bras. 2014;29(4):280-6. https://doi.org/10.1590/s0102-86502014000400010.

27. NIOSH, P. G. (s.d.). Tratto da https://www.cdc.gov/niosh/npg/npgd0454.html

28. Sicurezza, S. (s.d.). Tratto da https://www.pangas.ch/it/images/pangas_sdb_ossido-diazoto_i_tcm566-115248.pdf 
Figures

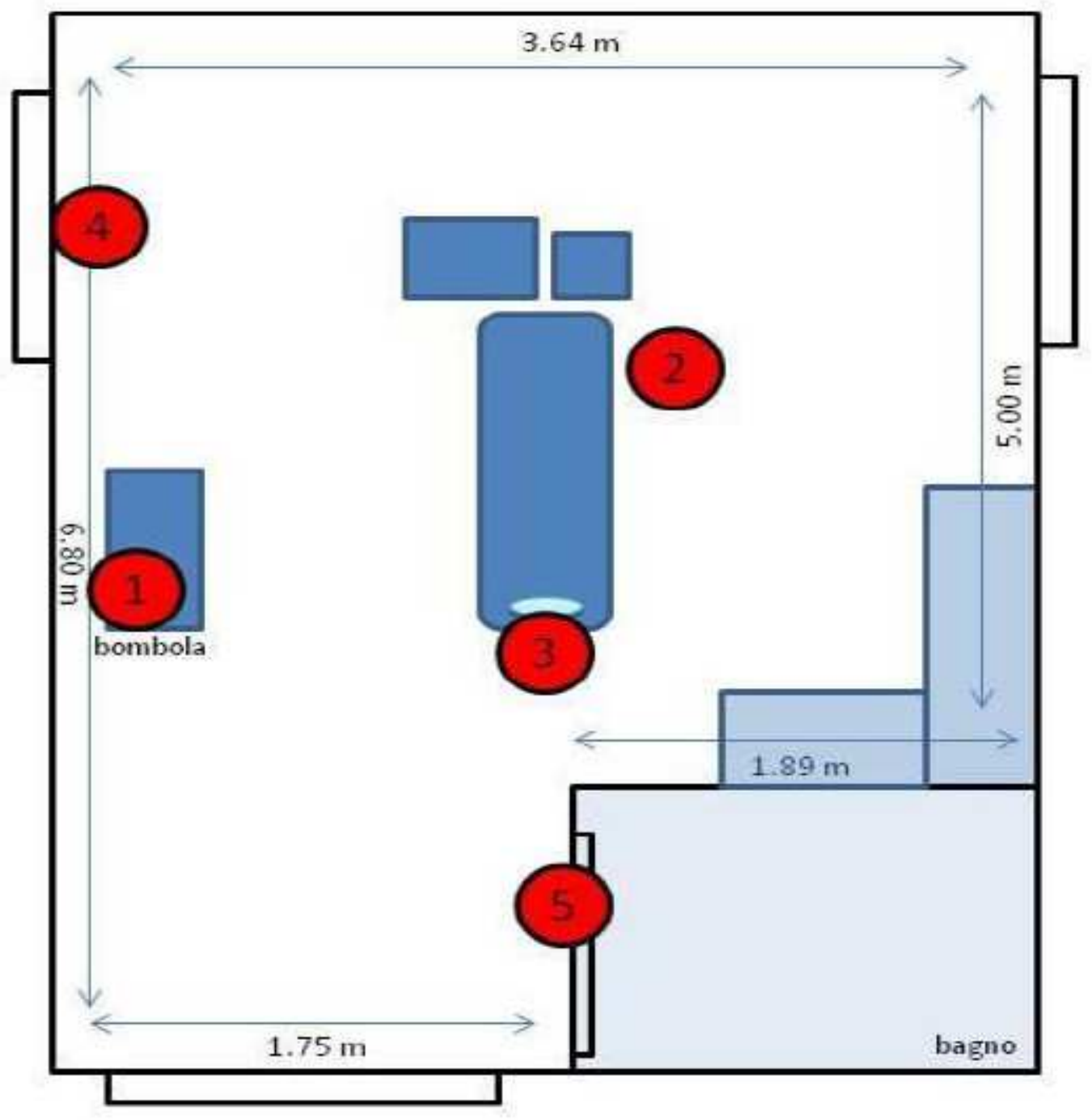

Figure 1

The measuring probes were placed in different point (1=Niki; $2=$ head-window; 3 head-door; $4=$ stabilized door; $5=$ access) 